\title{
Experiências do uso de novas Tecnologias no Ensino
}

\author{
Deymes Silva de Aguiar'1, Francisco M. A. de Araújo², Lucas Izidio de Sousa \\ Sampaio $^{3}$, Kauan Souza Portela ${ }^{4}$, Victor Castro Sousa Araújo ${ }^{5}$, Rian de Carvalho \\ da Costa ${ }^{6}$, Matheus Araujo Dantas ${ }^{7}$ \\ Instituto Federal de Ciências e Tecnologia do Piauí(IFPI) - Campus Parnaíba \\ Instituto Federal de Ciências e Tecnologia do Piaú(IFPI) - Campus Teresina \\ Rodovia BR-402, Km 3, s/n Baixa do Aragão, Parnaíba - PI

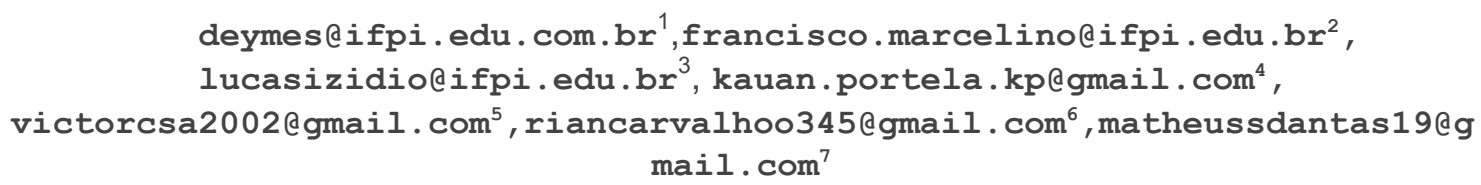

Resumo: O presente trabalho relata experiências vividas por professores e alunos do IFPI, fazendo uso de projetos educacionais com softwares Open Source com a manipulação de conhecimentos de programação e eletrônica, proporcionando a integração do currículo dos estudantes do ensino médio ao uso de tecnologias computacionais, possibilitando ao aluno uma aprendizagem mais significativa e atuante na produção de conhecimento. É discutida a necessidade de fazer uso de novas metodologias de ensino utilizando principalmente as tecnologias dentro do currículo escolar como uma necessidade real para uma mudança significativa da educação como também uma mudança na postura do professor e da escola.

\begin{abstract}
The present work reports experiences lived by IFPI teachers and students, making use of educational projects using Open Source software with the manipulation of programming and electronic knowledge, providing the integration of the curriculum of high school students to the use of computational technologies, enabling the student a more meaningful and active learning in the production of knowledge. The need to make use of new teaching methodologies using mainly technologies within the school curriculum as a real need for a significant change in education as well as a change in teacher and school posture is discussed.
\end{abstract}

\section{Introdução}

Nos dois últimos anos, o IFPI Campus Parnaíba e Campus Teresina têm se destacado com a realização de diversos projetos de pesquisas e extensão voltados para o processo de ensino aprendizagem. Com o uso da informática dos games no ensino, foram produzidos protótipos robóticos, aplicação de internet das coisas, aplicações de softwares no ensino. Para Moran(2018) as metodologias de ensino devem ter objetivo para que a aprendizagem ocorra de fato, além de colocar o aluno como ser proativo nesse processo. Mas em um mundo cada vez mais tecnológico é preciso readequar a forma como o processo de ensino é feito, saindo da esfera tradicionalista de ensino e procurando despertar no aluno o seu aspecto proativo, e uma dessas possibilidades é a 
VIII Congresso Brasileiro de Informática na Educação (CBIE 2019)

Anais do VIII Workshop de Desafios da Computação aplicada à Educação (DesafIE 2019)

aprendizagem por projeto. De acordo com França (2016), existe hoje nas escolas um novo aluno, onde este aprende de uma maneira diferente como seus professores aprenderam, principalmente com o uso de tecnologias, ouvindo músicas, interagindo com grupos de redes sociais, levando consigo para todos os lugares tecnologias como celulares e notebook.

\section{Trabalhos desenvolvidos}

Professores e alunos do IFPI Campus Parnaíba e Campus Teresina tem procurado vincular o uso de novas tecnologias ao ensino, através de projetos de pesquisa e extensão, utilizando o pensamento de integrar as novas tecnologias para uma aplicação real e conduzindo o aluno como agente participativo nos projeto.

Dentre os diversos trabalhos desenvolvidos, os estudantes foram capazes de criar games e robôs com plataformas Open Source usando a informática como ferramenta tecnológica, sendo capazes de aprender a robótica manipulando a programação e eletrônica, como também associar seus conhecimentos e produzir trabalhos científicos.

Alguns trabalhos estão descritos a seguir:

- Febrace (Feira Brasileira de Ciência e Tecnologia):

O trabalho desenvolvido e apresentado neste evento teve como foco a utilização da robótica educacional como ferramenta para o processo de ensino aprendizagem de Física para o ensino médio. Os estudantes foram capazes de de aprender a disciplina Física a partir do uso de ferramentas computacionais e eletrônica.

- $M N R$ (Mostra Nacional de Robótica):

Um dos objetivos é promover e valorizar o aprendizado interdisciplinar, colaborativo, investigativo e com foco na experimentação e inovação. Os estudantes, com ajuda dos professores orientadores, desenvolveram um experimento de Física sobre lançamento oblíquo, sendo automatizado utilizando a plataforma de prototipagem open-source arduino, aplicado no primeiro ano do Médio integrado. Outro trabalho apresentado foi a robótica educacional no ensino de Física, a partir do desenvolvimento de carrinhos controlados por arduino, sendo estudados conceitos físicos como velocidade, força, aceleração e eletrônica.

- $16^{\circ}$ Imagine Cup, Hackathon Vale-MA:

O projeto apresentado foi uma prótese de um braço com interação com nuvem virtual, que torna a adaptação e recuperação mais lúdica e divertida. Um dos diferenciais foi a utilização da gamificação para obtenção de dados e ajudar no processo de adaptação à prótese.

- Arduino Day:

O evento realizado no IFPI teve como objetivo mostrar projetos desenvolvidos por alunos de diversos cursos do ensino médio integrado ao médio utilizando plataforma Open Source Arduino como meio de despertar o protagonismo dos alunos, sempre relacionando com os assuntos vistos em sala de aula como meio de integrar a aprendizagem dentro e fora da sala de aula por meio de projetos educacionais.

- Scratch Day:

O evento foi organizado pelo IFPI - campus Parnaíba com o objetivo de promover o processo ensino aprendizagem sobre linguagem de programação de forma lúdica para estudantes da rede pública do município de Parnaíba - PI. 
VIII Congresso Brasileiro de Informática na Educação (CBIE 2019)

Anais do VIII Workshop de Desafios da Computação aplicada à Educação (DesafIE 2019)

- I Feira Tecnológica de Paulino Neves-MA:

Com base nos resultados e publicações dos projetos de robótica educacional, foi firmada uma parceria entre a secretaria de educação do município de Paulino Neves MA e o IFPI - campus Parnaíba para realização da I Feira Tecnológica da cidade, onde foram apresentados os trabalhos desenvolvidos no IFPI.

\section{Conclusão}

Propor novas metodologias de ensino através de novas ferramentas tecnológicas dentro do currículo escolar é de suma importância, pois em diversos trabalhos relatados, mostram-se pontuais, de poucos professores da escola e não integrado ao próprio currículo como é sugerido neste trabalho. Destaca-se também a necessidade da mudança na postura do professor que tem um grande desafio de não apenas repassar informações aos alunos, e sim ser capaz de propor projetos relacionados ao saber do indivíduo, sendo necessário o pensamento de que o ensino deve ser interdisciplinar e contextualizado. É preciso readequar a maneira de como o ensino é trabalhado nas escolas, projetos descritos nesse trabalho mostram exemplos claros de desenvolvimento cognitivo dos estudantes, que fazem deles, seres participativos no processo de ensino aprendizagem como também entes produtores da sua própria aprendizagem, fazendo do professor um facilitador nesse processo.Para que isso ocorra, é preciso adequar o currículo escolar voltados na realização de projetos de ensino baseada em projetos, dando ênfase a utilização da informática na educação como o uso de novas tecnologias e investimentos na capacitação dos docente e no protagonismo dos alunos.

\section{Referências:}

Aureliano, Viviane Cristina Oliveira; Tedesco, P. C. A. R. Avaliando o uso do Scratch como abordagem alternativa para o processo de ensino-aprendizagem de programação. In: XX Workshop sobre Educação em Computação. 2012. p. 10.

Bezerra, Fábio; Dias, Klissiomara. Programação de computadores no ensino fundamental: Experiências com logo e scratch em escola pública. In: XXXIV Congresso da SBC-XXII Workshop de Ensino de Computação, Brasília. 2014.

França, Alex Sandro de. Game, Web 2.0 e mundos virtuais em educação [recurso eletrônico]. $1^{\text {o }}$ edição. - São Paulo, SP : Cengage, 2016

Magalhães, Ricardo Rodrigues; Marengo, Rafael; Ferreira, Nayara Janice. Robótica educacional para inclusão social: relato de uma experiência extensionista em Lavras/MG. Revista Ciência em Extensão, v. 11, n. 3, p. 120-131, 2015.

Moran, José. Metodologias ativas para uma aprendizagem mais profunda. Metodologias ativas para uma educação inovadora: uma abordagem teórico-prática. Porto Alegre: Penso, p. 02-25, 2018. 